DOI:10.5392/I.JoC.2010.6.3.059

\title{
A Study on Validity of New Mobile Policies in Korea
}

\author{
Jemin Yang*, Jaechon Park \\ Graduate School of Information Technology \& Telecommunications \\ Inha University, Incheon, Korea
}

\begin{abstract}
The world mobile service is growing sharply and became bigger market than wired. So it is very needed to find the political way to promote mobile industry. The United States government recently decided to introduce new mobile policies for promoting mobile industry. Until now the telecommunications policies of the United States have affected policy developments for many countries including Korea. In this context, we studied the validity of introducing new mobile policies of the United States in Korea. We found that new mobile policies can cause the change of mobile market environment; mobile market power will be dispersed from network to content, application and devise, and new mobile market environment where consumers freely select and use network as well as content, application and devise will be made. Also we found empirically that if new policies are introduced in Korea, mobile industry will be promoted as Korean consumers use mobile services and goods quite actively in new mobile market. We think our results provide reasonable evidence to introduce new mobile policies in Korea.
\end{abstract}

Keywords: Wireless Open Access, DTV Bands, Network Neutrality, Mobile Policy.

\section{INTRODUCTION}

Mobile industry is emerging as the axis of telecommunications industry. The growth of wired telecommunication service around the world is being slowed in 2000s, but the world mobile service is growing sharply and became bigger market than wired after 2006 [1]. Also an average annual growth rate of mobile internet around the world is expected to reach to $13.6 \%$ from 2006 to 2013 , and a distribution rate of smart phone around the world is predicted to come to $19.4 \%$ in 2010 [2-3]. For such reasons, the potential of mobile industry can be evaluated highly.

But network operators have strong market power in the mobile industries, because they have spectrum resources as the bottleneck facility. So content providers, application providers and device manufacturers cannot but do limited business; network operators directly and indirectly intervene in the business of content providers, application providers and device manufacturers, and control the distribution of contents, applications and devices [4-5]. This fact is an obstacle to developing wireless industry, because it restricts the invention and distribution of new services and goods.

As a reaction to this problem, the United States recently introduced policies, Wireless Open Access, Spectrum Sharing in DTV bands and Network Neutrality. These policies have the goal to realize the potential of mobile industry by making the market environment which weakens the power of network operators and encourages other parties to enter the market.

\footnotetext{
*Corresponding author.E-mail : itip@inha.edu

Manuscript received Mar. 11, 2010 ; accepted Aug. 09, 2010
}

Until now the telecommunications policies of the United States have affected policy developments for many countries including Korea, and new policies of the United States are likely to have an influence on Korea's policy development. So it is time to verify the validity of introducing new policies in Korea.

Sometimes telecommunications policies have been successful, but sometimes resulted in failures. The reason why success and failure co-exist is that the policies have been developed primarily based on theoretical and historic backgrounds. Policy making therefore needs empirical market research. In this context, we intend to find the change of the mobile market environment induced by new policies, and empirically study that this new environment would be chosen and settled by Korean consumers.

\section{TELECOMMUNICATIONS POLICY AND INDUSTRY}

\subsection{Necessity of Policy}

The telecommunications industry has been considered to be the natural monopoly and the basic industries. So telecommunications policies have played a role in optimizing resources allocation through promoting competition [6], and they have also functioned as technology supply and adoption to bring about the innovation [7].

The heart of telecommunications policies is related to

This paper was supported by Inha University Research Grant. A preliminary version of this paper appeared in KSII The first International Conference on Internet (ICONI), December 1721, 2009, Bali, Indonesia. 
network. As the airport is essential for aviation industry and the harbor is essential for marine industry, so the network is necessary for telecommunications industry, and the company which has network can exercise industrial leverage [8]. In this context, establishing policies related network, many governments have made every effort to make the market environment where the network resources are used efficiently and the innovative services are produced.

The importance of telecommunications policy related network was proved historically and empirically. In 1956, the United States adopted No Harm to Public Network Principle by which any telephones could connect with any networks under no-interference terms. After the adoption of this principle, the telephone market was developed and promoted [9]. Also after the United States defined the computer communications as non-regulated area through Computer Inquiry in 1982, the services based on computer are evolved. Because it stimulated market entry and technology development [10].

And Musaev \& Bae(2008) found empirically that the reason why the growth of telecommunications industry was slow in Kazakhstan and Uzbekistan was resulted from poor telecommunications policies including network policies, and explained that well-planed policies is the key to the development of telecommunications industry [11].

\subsection{Evolution of Mobile Policy}

In mobile industry, the policies related to network have been discussed actively. Some pointed out that the minority to whom spectrum was allocated was using spectrum resources exclusively. To solve this problem, they suggested to create property rights to spectrum resources and to permit the market to bargain spectrum resources. They believed that if so, spectrum resources would be re-allocated toward creating maximum value regardless of original allocation [12]-[15]. According to the discussion, the United States granted spectrum lease in March 2005 [16], the United Kingdom approved spectrum trading in December 2004 [17], and Korea published the law for spectrum lease in December 2005 [18].

On the one hand, some pointed out that the conditions of spectrum allocation by which the use of spectrum resources was restricted to specific technology and service hindered the development of mobile industry. And they advocated the notion of spectrum liberalization which means that the limitation of technology and service is abolished [19],[20]. According to the discussion, the United States proposed interference temperature in November 2003 which is the concept for quantifying interference. The united States expected that interference temperature would make licensees freely change the license conditions, technology or service, without intereference [21]. And the United Kingdom announced introduction of spectrum usage rights. It permits the change of license conditions by negotiations between licensees [22].

Empirically analysys et al.(2004) studied the effects after introduction of spectrum bargain and liberalization in EU. They forecasted that as market entry becomes more active, the benefits equal to 1,070 million euro will be created every year, and as technology innovation accelerates, the benefits equal to 8,070 million euro will be created every year [23].

\section{NEW MOBILE POLICIES IN U.S.}

\subsection{Wireless Open Access}

The United States government decided to introduce wireless open access for 746 757Mhz and 776 787Mhz in July 2007 which were scheduled to be auctioned, as a method of using spectrum without network operators' control. Its bands were successfully bid contracted. The concept of wireless open access consists of Open Devices and Open Applications. Open devices guarantees free access to wireless networks by any devices, and open applications means that contents, applications, software and services can be freely distributed through wireless networks [24-25].

Therefore, wireless open access guarantee content providers, application providers and device manufacturers free access to networks.

\subsection{Spectrum Sharing in DTV Bands}

The United States, in compliance with part 15 of the CFR, allows everyone to use spectrum designated as unlicensed bands. Under this code, the sharing spectrum in licensed bands such as TV bands is not permitted. But the sharing of dividend spectrum (namely white space) which was designated in order to prevent television interference began to be considered under DTV conversion process. And the sharing of dividend spectrum was finally approved in November 2008.

This permission is to allow any business to build a network and provide portable and fixed services through every available device [26].

\subsection{Network Neutrality}

In the United States, the necessity of regulation for protecting free and open ideas in internet was discussed actively since 2005 when the United States announced policy statement on network neutrality, and the United States government finally published the draft rules on network neutrality in October 2009. The network neutrality is defined as the principles for prohibiting network operator's discriminative business. According to the rule, internet network operator should not prevent users from using lawful \& not-harmful content, applications and devices, and should treat content and applications nondiscriminatory manner [27]. These principles apply to all kinds of internet platforms including mobile.

So the rules on network neutrality give content providers, application providers and device manufacturers the right to offer contents, applications and devices to users freely via network.

\section{CHANGES OF MARKET AND FEATURES}

\subsection{Changes of Market}

Three new mobile policies of the United States enable parties in the mobile industry to access and use networks freely; they guarantee all parties free and open business in mobile industry. So new mobile policies inevitably result in new mobile market environments. We intend to find changes in the mobile market in view of industrial structure and consumers. 


\subsubsection{Industrial Structure}

Until now network operator have managed and controlled application, content and device as well as network in mobile industry. But, according to wireless open access, spectrum sharing in DTV bands and network neutrality rules, network operator has the obligation to provide own network to any application providers, content providers and device manufacturers who demand network, and they have a right to request any network operators to use networks which they choose.

As a result, the range of network operator's management and control is limited only to network. So the power of application providers, content providers and device manufacturers strengthen relatively.
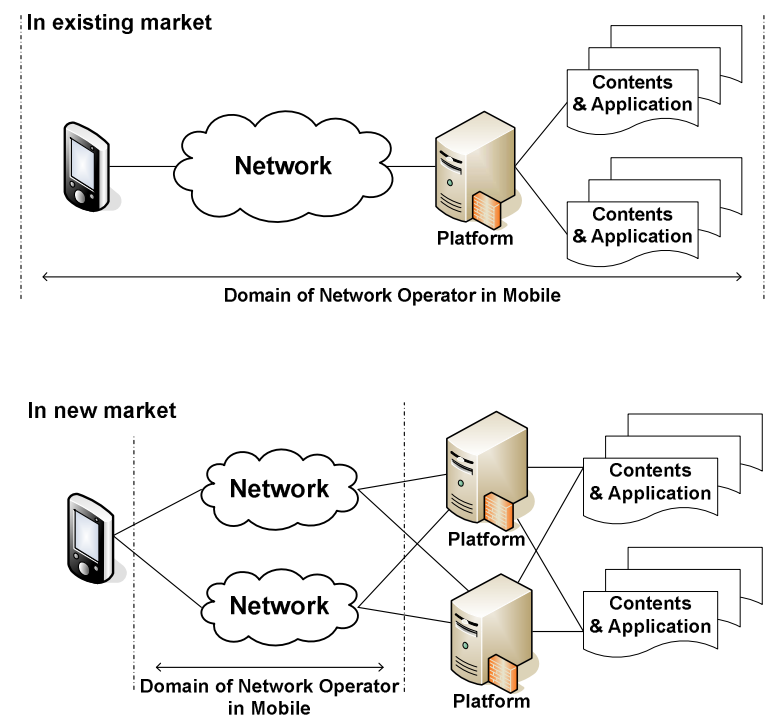

Fig. 1. Market Change in View of Industrial Structure

\subsubsection{Consumers}

The current market is led by a small number of network operators who have spectrum resources. Consumers are therefore strongly bound to a few network operators. This current market is defined as '1:N' relationship between the network operator and consumers. Under ' $1: \mathrm{N}$ ' relationship, consumers tend to use the mobile phone and mobile internet only by their subscribed networks because of high switching costs. And the network operators do self-centered business via their own networks.

However, under the new market, everyone can freely use networks through wireless open access, spectrum sharing in DTV bands and network neutrality rules. Therefore, the power of network operators is reduced, and that of the consumer grow. This means that switching costs are lowered, so consumers can freely select and use one of several networks based on their own requests. This relationship between network operators and consumer is defined as ' $\mathrm{N}: 1$ ' relationship.
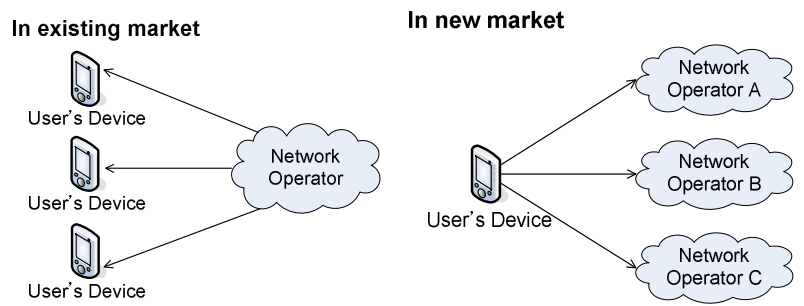

Fig. 2. Market Change in View of Consumer

\subsection{Features}

The new mobile market environment shows some special features, compared with those of the existing market. One is diversity. In the new market environment, content and application providers are allowed to deliver their products and services without agreements and permission from network operators. In addition, devices which aren't subordinate to a specific network and can connect diverse networks can appear. Under this process, the diversity of contents, applications and devices will be achieved.

The second is economic aspects. As everyone is able to build and operate networks without the possession of spectrum in the new environment, the consumer's option on network becomes more flexible. Also contents, applications and devices become diverse, as mentioned above. From these points of view, the new market is likely to stimulate competitiveness in networks, contents, applications and devices, and consequently the benefits from low prices and enhanced quality will be given to consumers.

The third is innovation. In the current market, goods and services are produced primarily for the network operator who has the market power; the production of contents, applications and devices has been subordinate to specific network. But in the new environment, the market power will be balanced. So there will be no limitation to develop goods and services. Ultimately, it will cause the appearance of innovative goods and services.

The fourth is alternative. The basic services such as voice and data in the current and new markets won't be much different, but there will be differences of the initiative to provide and use services. And when the new market has developed, current market-oriented services won't disappear completely. So current market-oriented services and new market oriented-services will have alternative relationships.

The fifth is necessity. As explained above, in new mobile market, diverse and creative goods and services will appear, and economical benefits will be given to consumer. These imply that new market can meet the needs of consumer more than existing market. Also if consumer's utilities increase by new market, consumer will more feel the necessity for mobile.

\section{EMPIRICAL ANALYSIS}

\subsection{Research Model}

We planned an empirical study using Technology Acceptance Model (TAM) to clarify whether the new mobile market can be chosen and settled by consumers in Korea. TAM 
is a model based on Theory of Reasoned Action (TRA), and describes consumers' behavior toward information technologies; it is useful to predict consumers' intention of using new goods and services in new environment based on information technologies [28-31].

So it was adopted in this study to clarify the Korean consumers' behavior regarding mobile goods and services in the new mobile market.

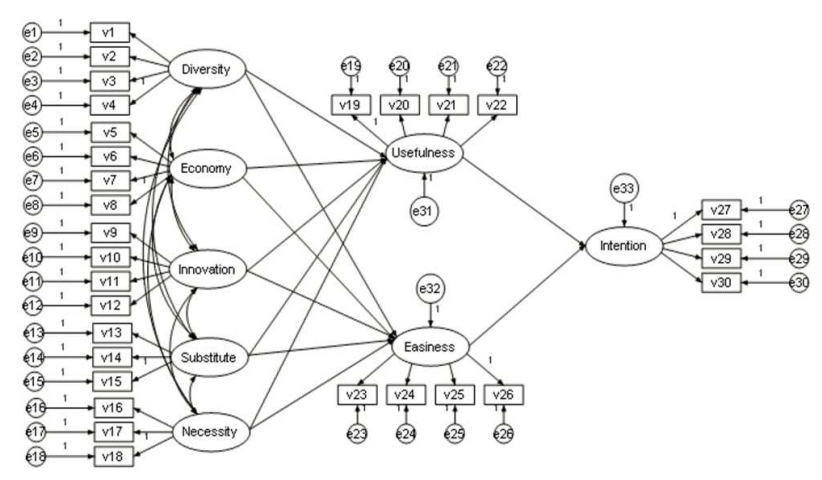

Fig. 3. Research Model

Based on TAM, this study developed the research model as shown in Fig. 3. This model designates 5 market features, diversity, economic aspects (named economy in the research model), innovation, alternative and necessity as independent variables, and perceived usefulness (named usefulness in the research model) and perceived ease of use (named easiness in the research model) as intermediate variables, and intention to use (named intention in the research model) as dependent variable. This model is to verify the hypothesis whether 5 market features actually have influence upon intention to use through perceived usefulness and perceived ease of use.

We conducted an on-line questionnaire based on the research model for one month in July 2009. The questionnaire was

\subsection{Reliability and Validity}

Reliability analysis is performed to check the consistency of respondents. We calculated Cronbach's Alpha by SPSS 12.0. If the value of Cronbach's Alpha is more than 0.7, reliability is believed to be sure [32]. All variables of this study exceeded 0.7 of Cronbach's Alpha.

Table 2. Results of Reliability Analysis

\begin{tabular}{|c|c|c|}
\hline Variables & Cronbach's Alpha & N of Item \\
\hline Diversity & 0.762 & 4 \\
\hline Economy & 0.747 & 4 \\
\hline Innovation & 0.859 & 4 \\
\hline Substitute & 0.714 & 3 \\
\hline Necessity & 0.827 & 3 \\
\hline Usefulness & 0.900 & 4 \\
\hline Easiness & 0.896 & 4 \\
\hline Intention & 0.906 & 4 \\
\hline
\end{tabular}

In order to verify whether all questionnaires used for measuring variables in the research model were suitable as measuring tools, factor analysis is required. We calculated CMIN, GFI, AGFI, CFI, NFI, IFI, TLI and RMR by performing Confirmatory Factor Analysis by AMOS 7.0. Generally their standard values are recommended that CMIN pvalue be higher than 0.01, CMIN/DF be lower than 2, GFI, CFI, NFI, IFI and TLI be higher than 0.9, AGFI be higher than 0.8 and RMR be lower than 0.05 [33]. As a result, all variables did not reach the standard value of CMIN p-value or CMIN/DF as shown in table 3. And economy did not reach the standard value of TLI.

But because the chi-square statistic is very sensitive regarding degree of freedom, it is not sufficient condition but necessary condition [34]. And TLI of economy is approximated to 0.9 . Therefore the composition of questionnaire is believed to be reasonable.

\subsection{Analysis Results}

Table 3. Results of Confirmatory Factor Analysis

\begin{tabular}{|c|c|c|c|c|c|c|c|c|c|c|c|}
\hline Index & N of Item & $\mathbf{x}^{\mathbf{2}}$ & $\mathbf{p}$ & $\mathbf{C M I N / D F}$ & $\mathbf{G F I}$ & AGFI & $\mathbf{C F I}$ & $\mathbf{N F I}$ & IFI & TLI & RMR \\
\hline Diversity & 4 & 5.472 & 0.065 & 2.736 & 0.988 & 0.941 & 0.988 & 0.981 & 0.988 & 0.963 & 0.031 \\
\hline Economy & 4 & 9.040 & 0.011 & 4.520 & 0.981 & 0.903 & 0.966 & 0.958 & 0.967 & 0.899 & 0.035 \\
\hline Innovation & 4 & 7.990 & 0.018 & 3.995 & 0.982 & 0.908 & 0.986 & 0.981 & 0.986 & 0.957 & 0.021 \\
\hline Substitute & 3 & 0.000 & 0.000 & 0.000 & 1.000 & 1.000 & 1.000 & 1.000 & 1.000 & 1.000 & 0.000 \\
\hline Necessity & 3 & 0.000 & 0.000 & 0.000 & 1.000 & 1.000 & 1.000 & 1.000 & 1.000 & 1.000 & 0.000 \\
\hline Usefulness & 4 & 14.868 & 0.001 & 7.434 & 0.966 & 0.830 & 0.977 & 0.974 & 0.977 & 0.932 & 0.024 \\
\hline Easiness & 4 & 7.868 & 0.020 & 3.934 & 0.984 & 0.919 & 0.989 & 0.986 & 0.990 & 0.968 & 0.017 \\
\hline Intention & 4 & 8.929 & 0.012 & 4.464 & 0.981 & 0.903 & 0.988 & 0.985 & 0.988 & 0.965 & 0.022 \\
\hline
\end{tabular}

targeted to Korean consumers who sufficiently understood the new mobile market through lecture and multimedia data, and the number of available respondents was 223 people.

Table 1. Demographic Profile of Respondents

\begin{tabular}{|c|c|c|c|c|c|}
\hline Sex & Number & Percent & Age & Number & Percent \\
\hline \multirow{2}{*}{ Male } & \multirow{2}{*}{149} & \multirow{2}{*}{$66.8 \%$} & $10 \mathrm{~s}$ & 6 & $2.7 \%$ \\
\cline { 4 - 6 } & & & $20 \mathrm{~s}$ & 171 & $76.7 \%$ \\
\hline \multirow{2}{*}{ Female } & \multirow{2}{*}{74} & \multirow{2}{*}{$33.2 \%$} & $30 \mathrm{~s}$ & 40 & $17.9 \%$ \\
\cline { 4 - 6 } & & Over $40 \mathrm{~s}$ & 6 & $2.7 \%$ \\
\hline Total & 223 & $100 \%$ & Total & 223 & $100 \%$ \\
\hline
\end{tabular}

The suitability of the model must be guaranteed to analyze our research model. However, as shown in table 4, the results of the test for goodness of fit by AMOS 7.0 indicated that the suitability of the initial model was not suitable. So we attempted to improve suitability by setting a covariance between deviations (setting covariance for e1-e6, e4-e17, e19e20 and e29-e30).

Although CMIN/P, GFI, NFI did not reach each standard value more or less, we decided to accommodate a modified model considering that CMIN p-value tends to be lower than 0.05 if the sample number is larger than 200 , and the suitability of CFI and NFI are near 0.9. 
Table 4. Results of Test for Goodness of Fit

\begin{tabular}{|c|c|c|c|c|c|c|c|c|}
\hline \multicolumn{8}{|c|}{ Initial model } \\
\hline CMIN/p & CMIN/DF & GFI & AGFI & CFI & NFI & IFI & TLI & RMR \\
\hline $867.902 / 0.000$ & 2.266 & 0.801 & 0.759 & 0.892 & 0.842 & 0.893 & 0.877 & 0.055 \\
\hline \multicolumn{8}{|c|}{ Modified model } \\
\hline CMIN/P & CMIN/DF & GFI & AGFI & CFI & NFI & IFI & TLI & RMR \\
\hline $358.862 / 0.000$ & 1.581 & 0.888 & 0.852 & 0.957 & 0.893 & 0.958 & 0.948 & 0.040 \\
\hline
\end{tabular}

The results of the hypothesis test targeting the modified model by AMOS 7.0 are shown as Table 5. Diversity affects easiness positively, necessity and innovation affect usefulness and easiness positively and substitute affects usefulness positively. Usefulness and easiness affects intention positively.

Table 5. Results of Verifying Hypothesis

\begin{tabular}{|l|c|c|c|l|}
\hline \multicolumn{1}{|c|}{ Link } & Estimate & S.E. & C.R. & P-value \\
\hline Diversity $\rightarrow$ Usefulness & -0.283 & 0.210 & -1.347 & 0.178 \\
\hline Diversity $\rightarrow$ Easiness & -0.830 & 0.358 & -2.321 & $0.020^{*}$ \\
\hline Necessity $\rightarrow$ Usefulness & 0.902 & 0.238 & 3.793 & $0.000^{* *}$ \\
\hline Necessity $\rightarrow$ Easiness & 0.759 & 0.297 & 2.554 & $0.011^{*}$ \\
\hline Innovation $\rightarrow$ Usefulness & 1.032 & 0.219 & 4.710 & $0.000^{* *}$ \\
\hline Innovation $\rightarrow$ Easiness & 1.061 & 0.314 & 3.381 & $0.000^{* *}$ \\
\hline Substitute $\rightarrow$ Usefulness & 0.548 & 0.255 & 2.145 & $0.032^{*}$ \\
\hline Substitute $\rightarrow$ Easiness & -0.222 & 0.303 & -0.733 & 0.463 \\
\hline Economy $\rightarrow$ Usefulness & 0.034 & 0.174 & 0.194 & 0.846 \\
\hline Economy $\rightarrow$ Easiness & 0.050 & 0.262 & 0.192 & 0.848 \\
\hline Usefulness $\rightarrow$ Intention & 0.628 & 0.095 & 6.585 & $0.000^{* *}$ \\
\hline Easiness $\rightarrow$ Intention & 0.411 & 0.089 & 4.629 & $0.000^{* *}$ \\
\hline Note: ${ }^{*} \mathrm{p}<0.05, * * \mathrm{p}<0.01$ & & & & \\
& & & & \\
&
\end{tabular}

Although economy did not show positive effects in this results, economy may affect intention to use indirectly. Because it is believed that economy is the most basic variable determining consumer behaviors. Therefore, if the new market is built in Korea by new policies, it will be settled successfully and consumers' consumption will be more stimulated.

\section{CONCLUSIONS}

We focused on new mobile policies of the United States whose aim is to foster mobile industry, and studied the validity of introducing these policies in Korea. We think that new mobile policies will cause the change of mobile market environment; mobile market power will be dispersed from network to content, application and devise, and user-oriented market where consumers freely select and use network as well as content, application and devise will be made. Also we found empirically that if new policies are introduced in Korea, the potential of mobile industry will come true and mobile industry will be promoted as Korean consumers consume mobile services and goods quite actively in new mobile market made by new mobile policies.

Korea government published 'mobile internet promotion plan' twice in 2009. It proves Korea government's interest in mobile industry; it just started to recognize the importance of mobile industry. At this present, this study has meaning in that we provide reasonable evidence that Korean mobile market can be promoted by new mobile policies. So the way to adapt new mobile policies to Korean circumstances should be studied from now on. We hope that this study can be the cornerstone of fostering Korean mobile industry.

\section{REFERENCES}

[1] TIA, "TIA 2008 Telecommunications Market Review and Forecast", 2008.

[2] Cowen and Company, "Wireless Equipment Industry Outlook", 2008.

[3] Credit Suisse, "Mobile Handsets", 2008.

[4] Hazlett, T. W., "The Wireless Craze, The Unlimited Bandwidth Myth, The Spectrum Auction Faux Pas, and the Punchline to Ronald Coase's "Big Joke": An Essay on Airwave Allocation Policy", Harv. J. L. \& Tech., vol. 14, no.2, 2001, pp.335-545.

[5] Lee, B. G., Kim, K. Y., Lee, C. H., Jeong, K. Y., "Analyzing Value Networks for Creating Stakeholder Values in Mobile Communications Industry", Korean Telecommunications Policy Review, vol.13, no.4, 2006, p.202.

[6] Vogelsang, I. \& Mitchell, B. M., Telecommunications Competition; The Last Ten Miles, MIT Press, 1996.

[7] Mowery, D., The Practice of Technology Policy, Stoneman(ed), 1995.

[8] Baumol, W. J. \& Sidak, J. G., Toward Competition in Local Telephony, MIT Press, 1994, p.9.

[9] Brick, G. W., The Telecommunications Industry: The Dynamics of Market Structure, Harvard University Press, 1981, pp.256-266.

[10] Lipman, A. D., Telecom Deregulation, 1987, pp.61 69.

[11] Musaev, E. \& Bae, J., "A study on Goverments' ICTrelated Policies for Development of ICTs in Kazakhstan and Uzbekistan", Journal of Internet Electronic Commerce Research, vol.8, no.3, 2008, pp.315 336.

[12] Coase, R. H., "The Federal Communications Commission", Journal of Law and Economics, vol.2, 1959, pp.1-40.

[13] Coase, R. H., "The Problem of Social Cost", Journal of Law and Economics, vol.3, 1960, pp.1-44.

[14] De Vany, A., Eckert, R. D., Meyers C. J., O'Hara, D. J. \& Scott, R. C., "A Property System for Market Allocation of the Electromagnetic Spectrum: A Legal-EconomicEngineering Study", Stanford Law Review, vol.21, no.6, 1969, pp.1499-1561.

[15] Matheson, R. J., "Flexible Spectrum Use Rights Tutorial", Proceedings of 2005 International Symposium on Advanced Radio Technologies(ISART'05), 2005, pp.157-167.

[16] FCC, "Report and Order and Further Notice of Proposed Rulemaking", WT Docket No.3-113, May 2003. 
[17] Ofcom, "The Wireless Telegraphy(Spectrum Trading) Regulation", Dec. 2004.

[18] MIC, "Radio Waves Act.", Dec. 2005.

[19] Hazlett, T. W., Hearst, E. D., May, R. J. \& Thierer, A. D., "Telecrisis: How Regulation Stifles High-speed Internet Access", Pacific Research Institute, 2003, pp.59-82.

[20] Lau, D. K. C., "Managing Radio Spectrum: Present and New Approaches", Proceedings of 2005 IEE Hong Seminar, Feb. 2005.

[21] FCC, "Notice of Inquiry and Notice of Proposed Rulemaking”, No.03-289, Nov. 2008.

[22] Ofcom, "Spectrum Usage Rights-Technology and Usage Neutral Access to the Radio Spectrum", Apr. 2006.

[23] Analysys, DotEcon, Hogan \& Hartson, "Study on Conditions and Options for Introducing Secondary Trading of Radio Spectrum in the European Community", May 2004.

[24] FCC, "Public Notice: Auction of 700Mhz Band Licenses Closes", DA 08-595, 2005.

[25] FCC, "Second Report and Order", No. 07-132, 2007.

[26] FCC, "Second Report and Order", No. 04-186, 2008.

[27] FCC, "Notice of Proposed Rulemaking", No. 09-191, 2009.

[28] Davis, F. D, "Perceived Usefulness, Perceived Ease of Use, and User Acceptance of Information Technology", MIS Quarterly, vol.13, no.3, 1989, pp.319-339.

[29] Adams, D. A., Nelson, R.R. \& Todd, P. A., "Perceived Usefulness, Ease of Use, and Usage of Information Technology : A Replication", MIS Quarterly, vol.16, no.2, 1992, pp.227-248.

[30] Agarwal R. \& Prasad, J., "The Role if Innovation Characteristics and Perceived Voluntariness in the Acceptance of Information Technology", Decision science, vol.28, no.3, 1997, pp.557-582.

[31] Lederer, A. L., Donna, J. M., Mark, P. S., \& Youlong, Z., "The Technology Acceptance Model and the World Wide Web", Decision Support Systems, vol.29, 2000, pp.269282.

[32] Hair, J. F., Anderson, R. E., Tatham, R. L., \& Black, W. C., Multivariate Data Analysis, 5th Edn., Prentice Hall, 1998.

[33] Bentler, P. M., \& Bonett, D. G., "Significance Tests and Goodness of Fit in the Analysis of Covariance Structures", Psychological Bulletin, no.88, 1980, pp.3751.

[34] Marsh, H. W., Balla, J. R., \& McDonald, R. P., "Goodness-of-Fit Indexes in Confirmatory Factor Analysis: The Effect of Sample Size", Psychological Bulletin, no.103, 1988, pp.391-411.

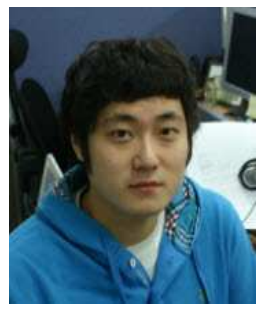

\section{Jemin Yang}

Jemin Yang is currently a doctoral student and a member of ITIP (Information Technology Industry and Policy) lab. in the Graduate School of Information Technology \& Telecommunications, Inha University. $\mathrm{He}$ received his BS degree in International Trade and Regional Studies from Inha University in 2005, and MS degree in Information \& Telecommunication Engineering from the Graduate School of Information Technology \& Telecommunications, Inha University in 2007. His research interests include IT Industry and e-business.

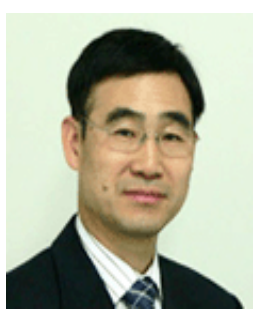

Jaechon Park

Jaechon Park received his BS degree in Applied Mathematics from The Engineering College of the Seoul National University in 1975, MS degree in O.R. from Georgia Institute of Technology in 1982 and Ph.D. in Economics from University of Hawaii at Manoa in 1988. He is currently a professor in the Graduate School of Information Technology and Telecommunications, Inha University since 2004. His research interests include the IT Industry and e-business. 